Department of High Temperature Strength of Structural Materials in Gas and Liquid Metal Media, Karpenko Physico-Mechanical institute of the NAS of Ukraine, Ukraine, Lviv, Naukova street, 5, E-mail: trushvasyl@gmail.com

\title{
KINETIC REGULARITIES OF HIGH-TEMPERATURE INTERACTION OF TITANIUM ALLOYS WITH OXYGEN-MEDIUM
}

Received: October 11, 2018 / Revised: November 23, 2018 / Accepted: December 26, 2018

(C) Trush V., 2018

Abstract. Titanium alloys are widely used in various aerospace, marine, chemical industries, medical, and military applications because these alloys have high specific strength, high Young's modulus, and excellent corrosion resistance. In particular, when a lot of organic composite materials such as carbon fibre-reinforced plastics (CFRP) are applied to aircraft components to decrease the weight reduction, titanium materials are also used because their thermal coefficient of expansion is similar to that of CFRP and titanium is not subject to damage by galvanic corrosion in contact with CFRP materials.

Oxygen can dissolve in titanium to form an interstitial solid solution in a large amount (34 at.\% in alpha titanium), it shows a strong hardness and mechanical strengthening on titanium matrix. Therefore, instead of expensive rare metals such as vanadium (V), oxygen (O) is usually used as a attractive interstitial solid solution strengthening element.

Results of experimental investigations of the influence of a oxygen-containing gaseous medium on the kinetics of interaction of titanium alloys of different structural classes $(\alpha-$, pseudo- $\alpha$, $(\alpha+\beta))$ are presented in this paper. It is established that under the same conditions of saturation $(T, \tau$, $P)$ the hardened layers of various parameters $(H, l)$ are formed on the titanium alloys. The monophase $\alpha$-titanium alloys VT1-0, VT5 and pseudo- $\alpha$-alloy OT4-1 are the most sensitive to the conditions of gas-saturation: gain of surface hardness and its gradient in the hardened layer increases sufficiently. With increasing of $\beta$-phase (OT4 $\rightarrow$ VT16) changing of the parameters of CTT has less influence on the hardness of surface layer, but the depth of the hardened zone is being increased with increasing of the temperature and exposure time.

Keywords: titanium alloy, oxygen, chemical-thermal treatment, hardness, mass gain.

\section{Introduction}

Due to the high specific strength, titanium and its alloys belong to the row of advanced constructional materials for aviation, where the replacement of steel parts with titanium leads to a significant reduction in the mass of constructions [1-4]. Therefore, in the global aircraft industry to increase the scientific and technical level of development and production it is planned to increase the share of titanium alloys in aircraft constructions. However, some of their natural physical-mechanical properties (increased reactivity to interact with oxygen and nitrogen, low antifriction and unstable fatigue properties, etc.) narrow the spectrum of use [5-8]. One of the ways to improve the above-mentioned properties is to engineering surface of titanium alloys, including by thermodiffusion saturation from a controlled gaseous medium [9-10].

\section{Problem formulation}

Unlike other methods of engineering surface, thermal-diffusion saturation is characterized by reproducibility of the process, a limited number of technological parameters that need to be controlled during processing, the ability to process specimens of arbitrary shape, including holes, high adhesion of 


\section{Vasyl Trush}

modified layers to the matrix, due to the possibility of forming a deep diffusion underlayer, which indicates the feasibility and effectiveness of its use in the engineering of the surface of titanium alloys.

To increase the functionality of titanium products used in aviation, it is necessary to develop principles for purposeful control of the intensity of physicochemical processes in the titanium system (titanium alloy) - a rarefied gaseous medium to form the necessary phase structural state of the surface layers and ensure the corresponding operational characteristics of the material (fatigue strength, durability and etc.).

At present, no regularities have been found for the surface solid-core strengthening of titanium alloys of various structural classes depending on the gas-dynamic and temperature-time parameters of the gaseous medium; The effect of the phase-structural state of the metal on the optimum level for improving fatigue properties and the level of solid-base strengthening of titanium alloys has not been studied.

The interaction of titanium with the interstitial elements combines various processes and reactions both in the gas phase and on the surface and in the near-surface layer of the metal: mass transfer in the gas phase; adsorption of gas molecules on the surface or their desorption; dissociation of adsorbed molecules and chemisorptions or recombination of adsorbed atoms into adsorbed molecules; the transition of the adsorbed atoms through the metal surface or the transition of the dissolved atoms into the adsorbed state; diffusion of gas atoms into the metal $[7,8]$. With the exception of the second stage, each of the successive stages of absorption can be controlling depending on the mass transfer conditions in the gas phase, the state of the surface, the temperature and the distribution of the concentration of gas dissolved in the metal [8].

\section{Statement of purpose and problems of research}

The aim of this work is to establish the main laws of high-temperature interaction of titanium alloys of different structural compositions with oxygen-containing gaseous medium.

\section{Experimental procedure and results}

Investigation of titanium alloys of different structural compositions: $\alpha$ - alloy- industrially (commercially) pure VT1-0 and also BT5-1 (5.0 Al) PT-7M (1.8...2.5 Al; 2.0...3,0 Zr); pseudo- $\alpha$ - alloy OT4-1 (3.5..5.0 Al; 0.8..2.0 Mn); $(\alpha+\beta)$ - alloy VT16 (1.8..3.8 Al; 4.5 ..6.5 Mo; 4..5.5 V).

For thermal treatment of titanium alloys, the plant for annealing in vacuum and in controllable gaseous media which had been developed in Karpenko Physico-Mechanical institute of the NAS of Ukraine was used.

Kinetic parameters of interaction of VT1-0, VT5, OT4-1 and VT16 alloys with rarefied gas medium.

As a result of interaction of titanium alloys with rarefied gas medium containing oxygen the processes of sublimation and phase formation may take place [11]. The processes of gas saturation and phase formation will be predominated at selected temperatures $(923 \ldots 1023 \mathrm{~K})$ and pressures $\left(6.6 \times 10^{-}\right.$ ${ }^{3} \ldots 6.6 \times 10^{-2} \mathrm{~Pa}$ ), accordingly to the analysis of changing of free energy of formation of solid solution of oxygen in titanium and titanium mono oxide (Fig. 1).

At the individual case, for alloys alloyed by manganese, molybdenum and vanadium, the sublimation is possible due to the formation of oxide compounds with high pressure of saturated vapor [12].Thus the gas saturation and phase formation increase the specimen mass of investigated titanium alloy, while sublimation - decreases.

The influence of temperature-time and gas-dynamical parameters $\left(\boldsymbol{T}=650,700,750^{\circ} \mathrm{C}\right.$, $\boldsymbol{\tau}=1,3,5 \mathrm{~h}, \boldsymbol{P}=6.6 \times 10^{-3}, 1.33 \times 10^{-2}, 6.6 \times 10^{-2} \mathrm{~Pa}$ ) of thermodiffusion saturation in controlled gas medium on the regularities of interaction of titanium alloys VT1-0, VT5, OT4-1 and VT16 is investigated by means of gravimetric analysis. The kinetic parameters of interaction of investigated titanium alloys determined by means of gravimetric analysis are resulted in the table 1.

Accordingly, to the obtained results for $\alpha$ - titanium alloys (VT1-0, VT5) the process of gas saturation is intensified with increasing of interaction temperature and pressure of gas medium (partial pressure of oxygen). The $\alpha$ - alloy VT1-0 (technical titanium) has the largest rate of interaction with rarefied gas medium containing oxygen under the all conditions. Alloying of titanium by $5 \% \mathrm{Al}-$ alloy VT5 - slows down slightly the rate of mass gain under the same conditions of interaction. 

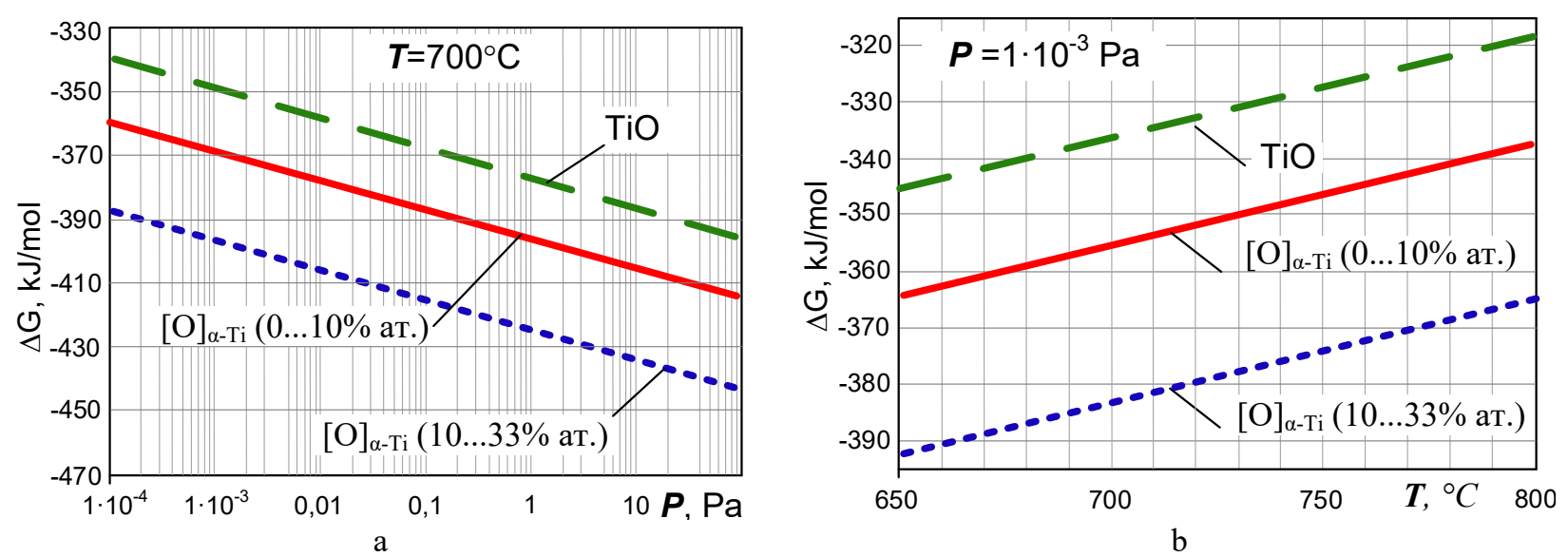

Fig. 1. Changes of free energy of formation of oxygen solid solutions in alpha titanium and titanium mono oxide as a function of $(a)$ oxygen pressure and $(b)$ temperature [11]

The mass loss caused by intensification of sublimation of alloying element $\mathrm{Mn}$ is possible for pseudo- $\alpha$-alloy OT4-1 (2\% $\beta$-phase) under definite conditions of interaction with rarefied gas medium. The ratio of parameters $\mathrm{T}$ and $\mathrm{P}$ exists for this alloy when the rates of the gas saturation and sublimation processes become comparable. For predomination of gas saturation processes, it is necessary to increase the partial pressure of oxygen or decrease the temperature of interaction.

Table 1

The specific mass gain of specimens of titanium alloys as a result of interaction with rarefied gas medium containing oxygen

\begin{tabular}{|c|c|c|c|c|c|c|c|c|c|c|}
\hline \multirow{3}{*}{ Alloy } & \multirow{2}{*}{$\boldsymbol{T},{ }^{\circ} \mathrm{C}$} & \multicolumn{9}{|c|}{$\Delta \boldsymbol{M} / \boldsymbol{S}\left(\mu \mathrm{g} / \mathrm{cm}^{2}\right)$ at residual pressure of gas medium } \\
\cline { 3 - 11 } & & $1 \mathrm{~h}$ & $3 \mathrm{~h}$ & $5 \mathrm{~h}$ & $1 \mathrm{~h}$ & $3 \mathrm{~h}$ & $5 \mathrm{~h}$ & $1 \mathrm{~h}$ & $3 \mathrm{~h}$ & $5 \mathrm{~h}$ \\
\hline & 650 & 3.46 & 9.905 & 15.98 & 4.58 & 12.9 & 20.61 & 7.95 & 21.34 & 33.14 \\
\hline \multirow{3}{*}{ VT1-0 } & 700 & 8.109 & 22.96 & 36.82 & 10,67 & 29.68 & 47.07 & 18.25 & 48,11 & 73.9 \\
& 750 & 17.416 & 48.83 & 77.85 & 22,82 & 62.68 & 98.64 & 38.45 & 99.49 & 151.23 \\
\hline & 650 & -0.10 & -0.31 & -0.52 & 3.18 & 9.55 & 16.0 & 7.25 & 22.00 & 36.75 \\
\hline \multirow{3}{*}{ OT4-1 } & 700 & -0.16 & -0.49 & -0.82 & 4.98 & 15.0 & 25.0 & 11.50 & 34.75 & 57.75 \\
\cline { 2 - 11 } & 750 & -0.24 & -0.73 & -1.23 & 7.47 & 22.0 & 37.0 & 17.25 & 52.00 & 86.50 \\
\hline \multirow{3}{*}{ VT16 } & 650 & 2.00 & 6.00 & 9.66 & 2.50 & 7.80 & 13.00 & 3.50 & 10.60 & 17.80 \\
\cline { 2 - 10 } & 700 & 2.32 & 7.00 & 11.60 & 2.80 & 8.80 & 14.20 & 4.10 & 12.60 & 22.50 \\
\cline { 2 - 10 } & 750 & 2.80 & 8.50 & 13.29 & 3.20 & 9.75 & 16.60 & 5.30 & 16.70 & 27.40 \\
\hline
\end{tabular}

Rate of gas saturation in rarefied gas medium decreased substantially with increasing of quantity of $\beta$-phase in alloys (VT16 $\rightarrow$ VT22). This is caused by decreasing of maximal solubility of oxygen in $\beta$-phase of titanium ( 6 at.\%) in comparison with $\alpha$-phase (33 at.\%). With increasing of interaction temperature this difference is appeared most appreciably. Therefore, it was concluded that alloys with large quantity of $\beta$ phase are the less sensitive to the changing of the conditions of interaction with rarefied gas medium containing oxygen.

Let's calculate the kinetic parameters as function of temperature accordingly with the data of mass changing of specimens of titanium alloys in rarefied gas medium containing oxygen.

All kinetic dependences in the 5-hour interval at the residual pressure $\boldsymbol{P}=1.33 \times 10^{-2} \mathrm{~Pa}$ follow linear dependence (1) satisfactorily. This indicates that surface reactions at the "metal-gas" interface are the controlling stage of the processes [3]:

$$
\Delta \boldsymbol{M} / \boldsymbol{S}=\left(\boldsymbol{k}^{\mathrm{P}} \cdot \boldsymbol{\tau} \pm \boldsymbol{A}\right) \cdot 10^{-2},\left[\mathrm{~g} / \mathrm{m}^{2}\right],
$$

where $\boldsymbol{k}^{\mathrm{p}}$ - coefficient of linear rate under constant pressure; $\boldsymbol{A}$ - confidence interval with possibility 0,98 .

The coefficient of linear rate under isobaric conditions of thermally activated process depends on the 


\section{Vasyl Trush}

absolute temperature $\boldsymbol{T}$ accordingly with Arrhenius equations [16]:

$$
\boldsymbol{k}^{\mathrm{P}}(\boldsymbol{T})=\boldsymbol{B} \cdot \exp \left(-\boldsymbol{E}_{\text {екс }} / \boldsymbol{R} \boldsymbol{T}\right) \pm \boldsymbol{C},\left[\mathrm{g} \cdot \mathrm{m}^{-2} \cdot \mathrm{h}^{-1}\right],
$$

where $\boldsymbol{B}$ - constant depending on temperature; $\boldsymbol{E}_{\text {екс }}$ - total energy of process activation; $\boldsymbol{C}$ - confidence interval with possibility 0.98 . Constants for equations (1) and (2) and experimental activation energy of process are presented in the Table 2 .

Table 2

Kinetic parameters of gas saturation of titanium alloys under isothermal conditions

\begin{tabular}{|c|c|c|c|c|c|c|}
\hline \multirow{3}{*}{ Alloy } & \multirow{3}{*}{$T,{ }^{\circ} \mathrm{C}$} & \multicolumn{5}{|c|}{ at $\boldsymbol{T}=700^{\circ} \mathrm{C}$} \\
\hline & & \multicolumn{2}{|c|}{ According to Formula (1) } & \multicolumn{3}{|c|}{ According to Formula (2) } \\
\hline & & $\boldsymbol{k}^{\mathrm{P}}, \mathrm{g} \cdot \mathrm{m}^{-2} \cdot \mathrm{h}^{-1}$ & $A, \mathrm{~g} \cdot \mathrm{m}^{-2}$ & $\boldsymbol{B}, \mathrm{g} \cdot \mathrm{m}^{-2} \cdot \mathrm{h}^{-1}$ & 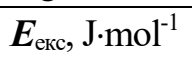 & $C, \mathrm{~g} \cdot \mathrm{m}^{-2} \cdot \mathrm{h}^{-1}$ \\
\hline \multirow{3}{*}{ VT1-0 } & 650 & 3.23 & 1.67 & \multirow{3}{*}{$4 \times 10^{7}$} & \multirow{3}{*}{7447.6} & \multirow{3}{*}{4.66} \\
\hline & 700 & 7.46 & 3.53 & & & \\
\hline & 750 & 15.8 & 4.21 & & & \\
\hline \multirow{3}{*}{ VT5 } & 650 & 2.44 & 0.59 & \multirow{3}{*}{$1 \times 10^{8}$} & \multirow{3}{*}{8140.6} & \multirow{3}{*}{3.91} \\
\hline & 700 & 6.02 & 2.96 & & & \\
\hline & 750 & 13.49 & 4.10 & & & \\
\hline \multirow{3}{*}{ VT16 } & 650 & 2.6 & 0.1 & \multirow{3}{*}{29.21} & \multirow{3}{*}{1350.8} & \multirow{3}{*}{1.07} \\
\hline & 700 & 2.86 & 0.87 & & & \\
\hline & 750 & 3.3 & 1.10 & & & \\
\hline \multirow{3}{*}{ OT4-1 } & 650 & 3.2 & 0.2 & \multirow{3}{*}{16585.2} & \multirow{3}{*}{4148.6} & \multirow{3}{*}{3.34} \\
\hline & 700 & 5.0 & 1.41 & & & \\
\hline & 750 & 7.38 & 2.87 & & & \\
\hline
\end{tabular}

All kinetic regularities follow linear dependence satisfactorily under isothermal conditions and various pressures accordingly with the data of thermogravimetry:

$$
\Delta \boldsymbol{M} / \boldsymbol{S}=\boldsymbol{k}^{\mathrm{T}} \boldsymbol{\tau} \pm \boldsymbol{F} \times 10^{-2},\left[\mathrm{~g} / \mathrm{m}^{2}\right],
$$

where $\boldsymbol{k}^{\mathrm{T}}$ - coefficient of linear rate under constant temperature $\left(700^{\circ} \mathrm{C}\right) ; \boldsymbol{F}$ - confidence interval with possibility 0.98 . Dependence of coefficient of linear rate under isothermal conditions on the residual pressure of medium is approximated satisfactorily by logarithmic dependence:

$$
\boldsymbol{k}^{\mathrm{T}}(\boldsymbol{P})=[\boldsymbol{H}+\boldsymbol{J} \cdot \ln (\boldsymbol{P})] \pm \boldsymbol{K},\left[\mathrm{g} \cdot \mathrm{m}^{2} \cdot \mathrm{h}^{-1}\right],
$$

where $\boldsymbol{H}, \boldsymbol{J}$ - constants depending on pressure; $\boldsymbol{K}$ - confidence interval with possibility 0.98 .

Coefficients for equations (3) and (4) are presented in Table 3.

\begin{tabular}{|c|c|c|c|c|c|c|}
\hline \multirow{3}{*}{ Alloy } & \multirow{3}{*}{$\boldsymbol{P} \times 10^{2}, \mathrm{~Pa}$} & \multicolumn{5}{|c|}{ at $\boldsymbol{T}=700^{\circ} \mathrm{C}$} \\
\hline & & \multicolumn{2}{|c|}{ According to Formula (3) } & \multicolumn{3}{|c|}{ According to Formula (4) } \\
\hline & & $\boldsymbol{k}^{\mathrm{T}}, \mathrm{g} \cdot \mathrm{m}^{-2} \cdot \mathrm{h}^{-1}$ & $F, g \cdot m^{-2}$ & $\boldsymbol{H}, \mathrm{g} \cdot \mathrm{m}^{-2} \cdot \mathrm{h}^{-1}$ & $\boldsymbol{J}, \mathrm{g} \cdot \mathrm{m}^{-2} \cdot \mathrm{h}^{-1}$ & $\boldsymbol{K}, \mathrm{g} \cdot \mathrm{m}^{-2} \cdot \mathrm{h}^{-1}$ \\
\hline \multirow{3}{*}{ VT1-0 } & 0.66 & 7.46 & 1.25 & \multirow{3}{*}{24.357} & \multirow{3}{*}{3.3804} & \multirow{3}{*}{1.05} \\
\hline & 1.33 & 9.57 & 1.53 & & & \\
\hline & 6.6 & 15.2 & 2.24 & & & \\
\hline \multirow{3}{*}{ VT5 } & 0.66 & 5.3 & 0.64 & \multirow{3}{*}{10.243} & \multirow{3}{*}{0.98} & \multirow{3}{*}{0.77} \\
\hline & 1.33 & 6.02 & 0.90 & & & \\
\hline & 6.6 & 7.57 & 1.68 & & & \\
\hline \multirow{3}{*}{ VT16 } & 0.66 & 2.32 & 0.24 & \multirow{3}{*}{6.8862} & \multirow{3}{*}{0.9116} & \multirow{3}{*}{0.37} \\
\hline & 1.33 & 2.86 & 0.74 & & & \\
\hline & 6.6 & 4.41 & 1.05 & & & \\
\hline \multirow{3}{*}{ OT4-1 } & 0.66 & -0.16 & 0.063 & \multirow{3}{*}{25.189} & \multirow{3}{*}{4.8973} & \multirow{3}{*}{2.11} \\
\hline & 1.33 & 5.00 & 0.41 & & & \\
\hline & 6.6 & 11.56 & 0.77 & & & \\
\hline
\end{tabular}

Table 3

\section{Kinetic parameters of gas saturation of titanium alloys under isothermal conditions}




\section{Kinetic Regularities of High-temperature Interaction of Titanium Alloys with Oxygen-Medium}

Effect of temperature and time on surface metal hardness and hardening zone depth.

Formation of interstitial solid solution in the metal during diffusion saturation of titanium alloys by gases in rarefied gas medium (mainly by oxygen) is bound up with strong distortion of crystallographic lattice (Fig. 2) and as a result of this with essential increasing of hardness of metal. Therefore, the parameters of gas-saturated layers were determined by means of two methods: using microhardness that was measured on both surface and cross section of metallographic sample made of the gas-saturated specimen and changing in parameters of crystallographic lattice. The last one method is more complex and laborious; therefore, it was used only for determination of parameters of maximally hardened layer. Depth of gas-saturated layer recognizes as a distance from the surface where increasing of hardness caused by dissolution of oxygen is equal to the measurement error.

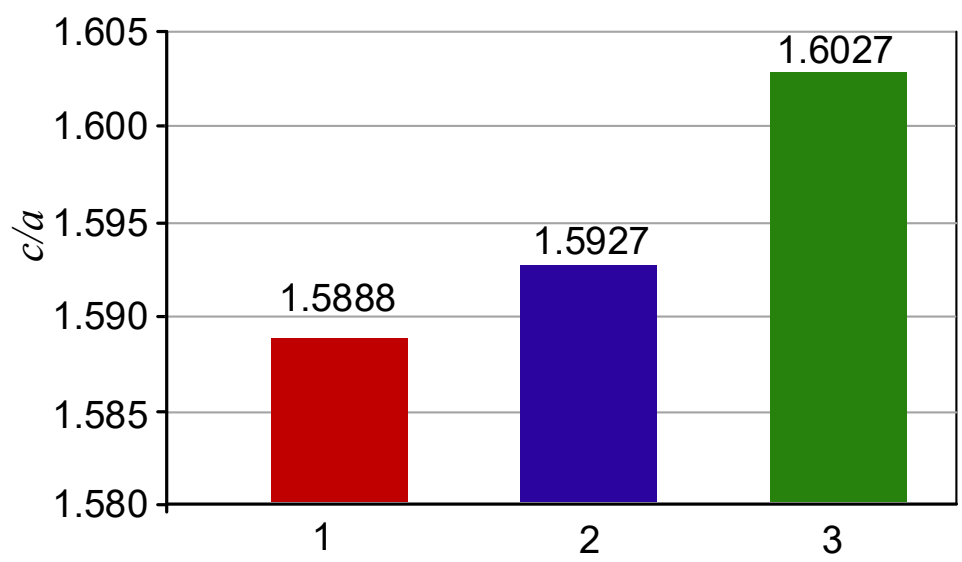

Fig. 2. Changing of ratio of parameters of crystallographic lattice (c / a) of titanium alloy surface layer VT1-0 as a function of CTT regime: 1 - in initial state; 2 - after CTT $-\boldsymbol{T}=650^{\circ} \mathrm{C}, \boldsymbol{P}=6.6 \times 10^{-3} \mathrm{~Pa}, \boldsymbol{\tau}=5 \mathrm{~h} ; 3-$ after CTT -

$$
\boldsymbol{T}=750{ }^{\circ} \mathrm{C}, \boldsymbol{P}=6.6 \times 10^{-3} \mathrm{~Pa}, \boldsymbol{\tau}=5 \mathrm{~h}
$$

The experimentally obtained results of influence of parameters of thermodiffusion saturation on the gain of surface hardness $\boldsymbol{K}$ of investigated titanium alloys are presented in the tables 4-6 $\left(\boldsymbol{K}=\left(\left(\boldsymbol{H}_{\mu}{ }^{\mathrm{s}}-\right.\right.\right.$ $\left.\left.\boldsymbol{H}_{\mu}{ }^{c}\right) / \boldsymbol{H}_{\mu}{ }^{\mathrm{c}}\right) \times 100 \%$, where: $\boldsymbol{H}_{\mu}{ }^{\mathrm{s}}$ - surface hardness of metal; $\boldsymbol{H}_{\mu}{ }^{\mathrm{c}}-$ bulk hardness) and depth of gas-saturated zone $\boldsymbol{l}$, determined by durometry.

Table 4

Gain of surface hardness of titanium alloys as a result of interaction with rarefied gas medium containing oxygen

\begin{tabular}{|c|c|c|c|c|c|c|c|c|c|c|}
\hline \multirow{3}{*}{ Alloy } & \multirow{2}{*}{$\boldsymbol{T},{ }^{\circ} \mathrm{C}$} & \multicolumn{9}{|c|}{$\boldsymbol{P}(\%)$ at residual pressure of gas medium } \\
\cline { 3 - 11 } & & $1 \mathrm{~h}$ & $3 \mathrm{~h}$ & $5 \mathrm{~h}$ & $1 \mathrm{~h}$ & $3 \mathrm{~h}$ & $5 \mathrm{~h}$ & $1 \mathrm{~h}$ & $3 \mathrm{~h}$ & $5 \mathrm{~h}$ \\
\hline & 650 & 41 & 66 & 81 & 56 & 85 & 103 & 80 & 121 & 143 \\
\hline \multirow{3}{*}{ VT1-0 } & 700 & 37 & 61 & 75 & 49 & 78 & 96 & 74 & 113 & 134 \\
\cline { 2 - 11 } & 750 & 22 & 37 & 47 & 30 & 48 & 60 & 45 & 72 & 88 \\
\hline \multirow{3}{*}{ VT5 } & 650 & 30 & 47 & 58 & 37 & 58 & 70 & 52 & 78 & 92 \\
\cline { 2 - 12 } & 700 & 28 & 45 & 56 & 35 & 56 & 67 & 50 & 75 & 89 \\
\cline { 2 - 11 } & 750 & 6.5 & 11 & 15 & 10 & 18 & 22 & 20 & 32 & 40 \\
\hline \multirow{3}{*}{ OT4-1 } & 650 & 38 & 66 & 86 & 33 & 58 & 75 & 11 & 18 & 24 \\
\cline { 2 - 11 } & 700 & 17 & 30 & 38.9 & 28 & 50 & 64 & 26 & 45 & 59 \\
\cline { 2 - 11 } & 750 & 9 & 17 & 22 & 8 & 15 & 19 & 13 & 23 & 29 \\
\hline \multirow{3}{*}{ VT16 } & 650 & 25 & 47 & 60.2 & 24 & 41 & 54 & 22 & 38 & 48.8 \\
\cline { 2 - 11 } & 700 & 5 & 9 & 11.8 & 3 & 5 & 6.7 & 1 & 2 & 2.5 \\
\cline { 2 - 11 } & 750 & 0.45 & 0.77 & 1 & 0.4 & 0.8 & 0.76 & 0.4 & 0.8 & 1 \\
\hline
\end{tabular}


Table 5

Dimension of gas-saturated layer on titanium alloys as a result of interaction with rarefied gas medium containing oxygen

\begin{tabular}{|c|c|c|c|c|c|c|c|c|c|c|}
\hline \multirow[t]{3}{*}{ Alloy } & \multirow{3}{*}{$T,{ }^{\circ} \mathrm{C}$} & \multicolumn{9}{|c|}{$\boldsymbol{l}(\mu \mathrm{m})$ at residual pressure of gas medium } \\
\hline & & \multicolumn{3}{|c|}{$\boldsymbol{P}=6.6 \cdot 10^{-3} \mathrm{~Pa}$} & \multicolumn{3}{|c|}{$\boldsymbol{P}=1.33 \cdot 10^{-2} \mathrm{~Pa}$} & \multicolumn{3}{|c|}{$\mathbf{P}=6.6 \cdot 10^{-2} \mathrm{~Pa}$} \\
\hline & & $1 \mathrm{~h}$ & $3 \mathrm{~h}$ & $5 \mathrm{~h}$ & $1 \mathrm{~h}$ & $3 \mathrm{~h}$ & $5 \mathrm{~h}$ & $1 \mathrm{~h}$ & $3 \mathrm{~h}$ & $5 \mathrm{~h}$ \\
\hline \multirow{3}{*}{ VT1-0 } & 650 & 6 & 13 & 18 & 7 & 14 & 20 & 8 & 16 & 22 \\
\hline & 700 & 10 & 22 & 30 & 11 & 24 & 33 & 13 & 27 & 36 \\
\hline & 750 & 19 & 38 & 53 & 21 & 41 & 57 & 24 & 46 & 62 \\
\hline \multirow{3}{*}{ VT5 } & 650 & 5 & 11 & 16 & 6 & 12 & 18 & 7 & 14 & 20 \\
\hline & 700 & 7 & 17 & 25 & 9 & 20 & 28 & 11 & 22 & 31 \\
\hline & 750 & 8 & 22 & 32 & 12 & 28 & 40 & 17 & 35 & 49 \\
\hline \multirow{3}{*}{ OT4-1 } & 650 & 13 & 22 & 29 & 26 & 45 & 58 & 36 & 62 & 80 \\
\hline & 700 & 20 & 35 & 45 & 33 & 57 & 73 & 45 & 77 & 100 \\
\hline & 750 & 30 & 52 & 67 & 40 & 70 & 90 & 54 & 93 & 120 \\
\hline \multirow{3}{*}{ VT16 } & 650 & 19 & 48 & 71 & 22 & 53 & 76 & 26 & 60 & 85 \\
\hline & 700 & 3 & 10 & 33 & 5 & 40 & 70 & 27 & 73 & 109 \\
\hline & 750 & 2 & 5 & 40 & 1 & 55 & 100 & 37 & 108 & 163 \\
\hline
\end{tabular}

The results concern the determination of parameters of crystallographic lattice of specimens of investigated alloys after different regimes of thermodiffusion saturation are presented in Table 6.

Table 6

Changing of parameter of crystallographic lattice of titanium alloys as a result of interaction with rarefied gas medium containing oxygen

\begin{tabular}{|c|c|c|c|c|}
\hline Operating mode of CTT & Allov & $a$ & $c$ & $c / a$ \\
\hline \multirow{4}{*}{ Initial state } & VT1-0 & 2.9481 & 4.6842 & 1.5889 \\
\hline & VT5 & 2.9286 & 4.6746 & 1.5962 \\
\hline & OT4-1 & 2.9427 & 4.6823 & 1.5911 \\
\hline & VT16 & 2.9287 & 4.6674 & 1.5936 \\
\hline \multirow{4}{*}{$750^{\circ} \mathrm{C}, 5.3 \times 10^{-3} \mathrm{~Pa}, 5 \mathrm{~h}$} & VT1-0 & 2.9484 & 4.6860 & 1.5893 \\
\hline & VT5 & 2.9281 & 4.6753 & 1.5967 \\
\hline & OT4-1 & 2.9419 & 4.6856 & 1.5927 \\
\hline & VT16 & 2.9298 & 4.6707 & 1.5942 \\
\hline \multirow{4}{*}{$750^{\circ} \mathrm{C}, 1.3 \times 10^{-2} \mathrm{~Pa}, 5 \mathrm{~h}$} & VT1-0 & 2.9496 & 4.6979 & 1.5927 \\
\hline & VT5 & 2.9263 & 4.6729 & 1.5968 \\
\hline & OT4-1 & 2.9426 & 4.6879 & 1.5931 \\
\hline & VT16 & 2.9284 & 4.6687 & 1.5942 \\
\hline \multirow{4}{*}{$750^{\circ} \mathrm{C}, 6.6 \times 10^{-2} \mathrm{~Pa}, 5 \mathrm{~h}$} & VT1-0 & 2.948 & 4.7248 & 1.6027 \\
\hline & VT5 & 2.9329 & 4.7050 & 1.6042 \\
\hline & OT4-1 & 2.9426 & 4.6911 & 1.5942 \\
\hline & VT16 & 2.9301 & 4.6706 & 1.5940 \\
\hline
\end{tabular}

The regularities of thermodiffusion saturation intrinsic for all investigated alloys were revealed basing on the analysis of obtained results, namely: parameters of gas-saturated layer $\boldsymbol{H}_{\mu}{ }^{\mathrm{s}}, \Delta \boldsymbol{H}_{\mu}{ }^{\mathrm{s}}$ and $\boldsymbol{l}$ increase with increasing of saturation time under the same pressure of gas medium and temperature (Fig. 3, 4); the depth of gas saturated zone $\boldsymbol{l}$ is increased and value of relative gain of surface hardness $\Delta \boldsymbol{H}_{\mu}{ }^{\mathrm{s}}$ is decreased with increasing of saturated temperature in the range $650 \ldots 750^{\circ} \mathrm{C}$ (Fig. 5). 


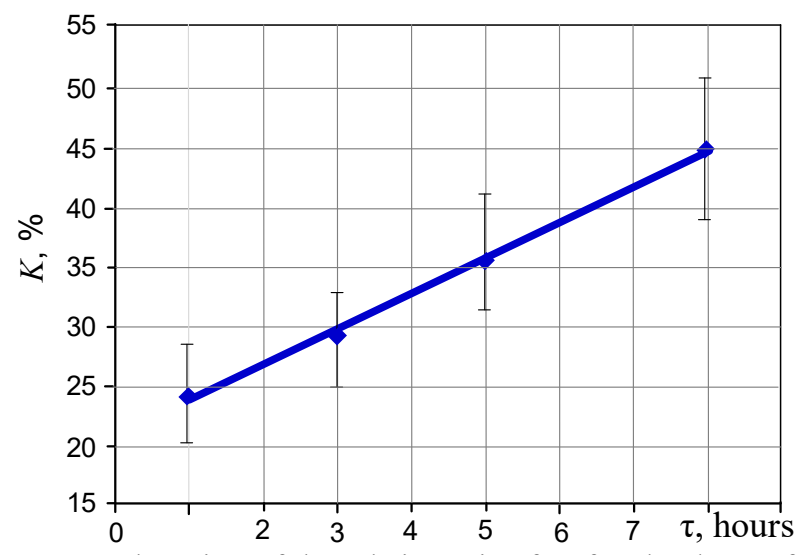

Fig. 3. Changing of the relative gain of surface hardness of titanium alloy VT1-0 under CTT $\left(\boldsymbol{T}=750^{\circ} \mathrm{C}\right.$,

$\left.\boldsymbol{P}=1.3 \times 10^{-3} \mathrm{~Pa}\right)$ depending on exposure time

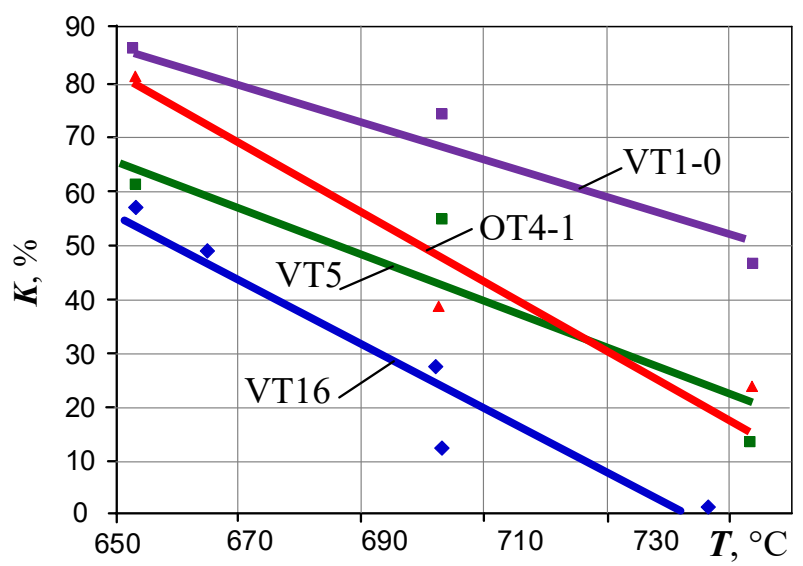

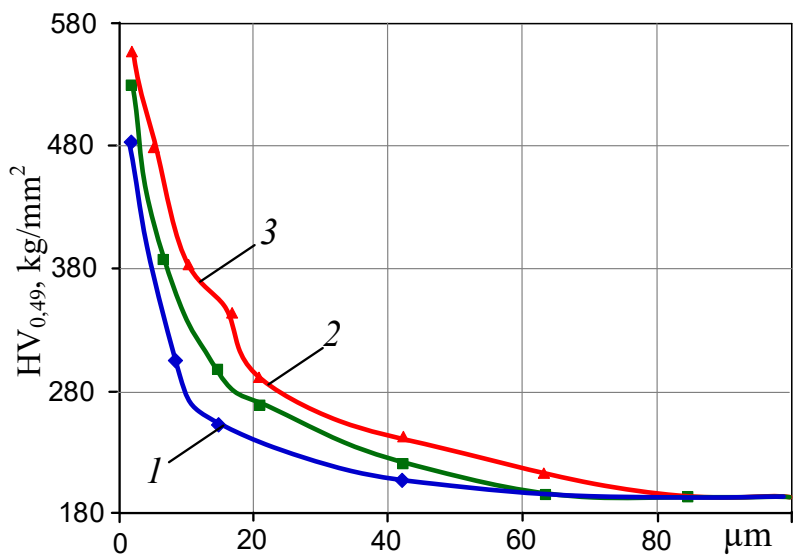

Fig. 4. Distribution of microhardness through the section of the specimens of alloy VT1-0 after CTT

$\left(\boldsymbol{P}=1.3 \times 10^{-3} \mathrm{~Pa}, \boldsymbol{\tau}=5 \mathrm{~h}\right)$ at temperatures: $1-650^{\circ} \mathrm{C} ; 2-$ $700^{\circ} \mathrm{C} ; 3-750^{\circ} \mathrm{C}$

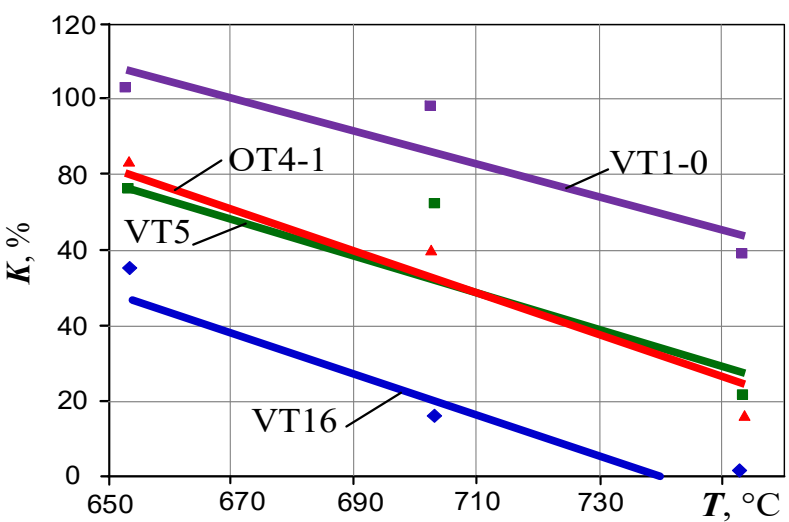

$b$

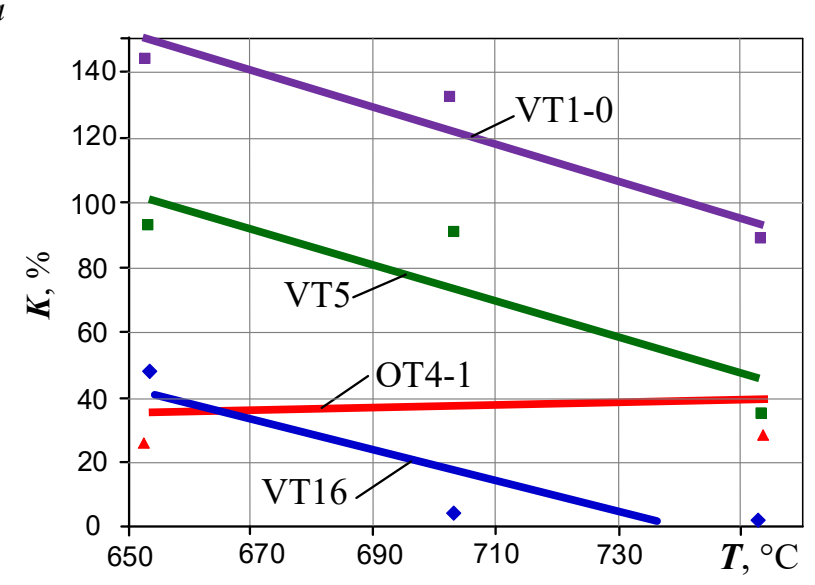

$c$

Fig. 5. Changing of the gain of surface hardness depending on interaction temperature with gas medium: $a-P=6.6 \times 10^{-3} \mathrm{~Pa}$; $b-\boldsymbol{P}=1.3 \times 10^{-2} \mathrm{~Pa} ; c-\boldsymbol{P}=6.6 \times 10^{-2} \mathrm{~Pa}$

The first regularity is connected with increasing of concentration of interstitial impurity in surface layer of metal with time and its penetration on the greater depth. The second regularity can be explained by acceleration of withdrawal of interstitial impurities from the surface due to increasing of its diffusivity in $\alpha$ - and $\beta$-titanium with increasing of temperature (Fig. 6). Under such conditions, the flow of oxygen from the medium to the metal surface becomes smaller in comparison with withdrawal flow owing to diffusion from the surface into the metal depth. 


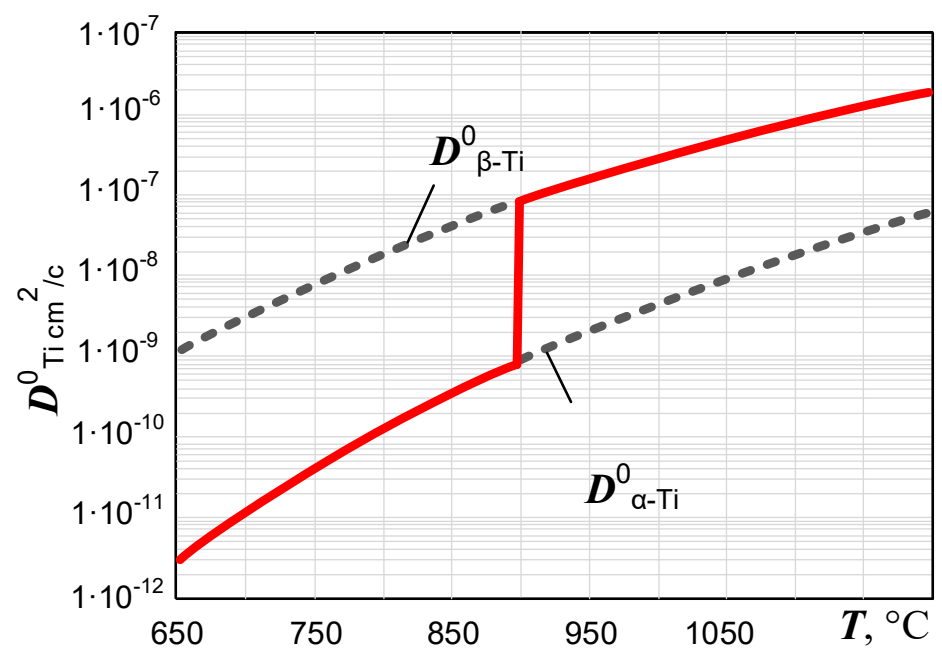

Fig. 6.Temperature dependence of oxygen diffusion coefficient in titanium [3]

The phase composition of titanium alloys influences essentially on the quantitative index of saturation at not influencing on the qualitative appearance of determined regularities. The maximal dissolution of oxygen in $\alpha$-phase of titanium composes 33 at.\%, while in $\beta$-phase - only 6 at. $\%$. Therefore in the titanium alloys with large content of $\alpha$-phase (VT1-0, VT5 and pseudo- $\alpha$-alloy OT4-1) during thermodiffusion saturation in gas medium the gas-saturated layers with high gradient of hardness are formed (Fig. 7).
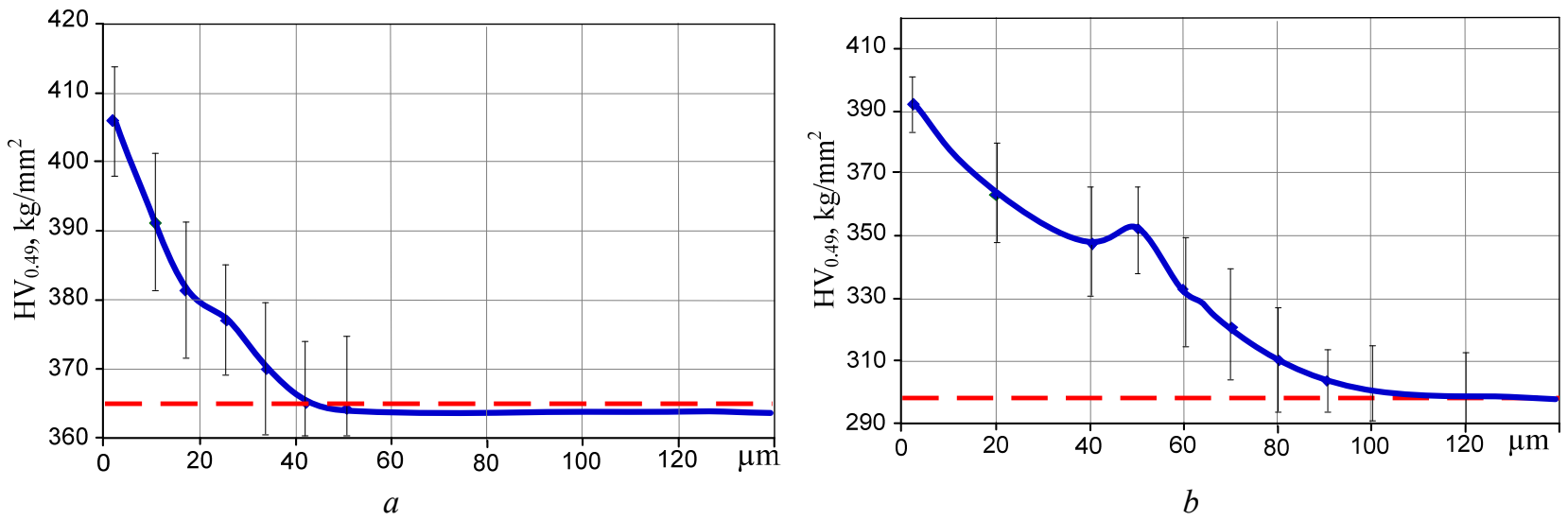

Fig. 7. Distribution of microhardness in the surface layer of alloy $(a)$ VT5 and $(b)$ OT4-1 after CTT $\left(\boldsymbol{T}=750{ }^{\circ} \mathrm{C}\right.$,

$$
\left.\boldsymbol{P}=6.6 \times 10^{-2} \mathrm{~Pa}, \boldsymbol{\tau}=5 \mathrm{~h}\right)
$$

Gas saturated layer with high gradient of hardness is formed on the $(\alpha+\beta)$-alloy VT16 at the low temperatures of saturation (Fig. 8).

The values of coefficient $\boldsymbol{K}$ representing the relative gain of surface hardness are higher sufficiently for $\alpha$-alloys VT1- 0 and VT5 in comparison with pseudo- $\alpha$-alloy OT4-1 and $(\alpha+\beta)$-alloy VT16 under the same conditions of thermodiffusion saturation. From another hand, the oxygen diffusion coefficient in $\beta$ titanium is high of order of magnitude in comparison with $\alpha$-phase $\left(\boldsymbol{D}_{\beta-\mathrm{Ti}}=3 \times 10^{-10} \mathrm{~cm}^{2} / \mathrm{c} ; \boldsymbol{D}_{\alpha-\mathrm{Ti}}=2 \times 10^{-9}\right.$ $\mathrm{cm}^{2} / \mathrm{c}$ at $\left.800{ }^{\circ} \mathrm{C}[3,4]\right)$. Therefore, with increasing in the alloys of volumetric content of $\beta$-phase the depth of gas-saturated zone $\boldsymbol{l}$ is increased. Thus on the surface of alloy VT16 the gas-saturated layers with depth of 2-2,5 time bigger in comparison with $\alpha$-alloy VT1-0 are formed (160 and $60 \mu \mathrm{m}$ correspondingly after treatment under condition $\boldsymbol{T}=750{ }^{\circ} \mathrm{C}, \boldsymbol{P}=6.6 \times 10^{-2} \mathrm{~Pa}, \boldsymbol{\tau}=5 \mathrm{~h}$ ).

Gas-saturation and sublimation influence during thermodiffusion saturation not only on the hardness but also on change the state of surface and phase-structural state of near-surface layer of metal. Thus, because of sublimation and surface diffusion the grain boundaries showed up, on the some grains the characteristic step-like microrelief is developed. 

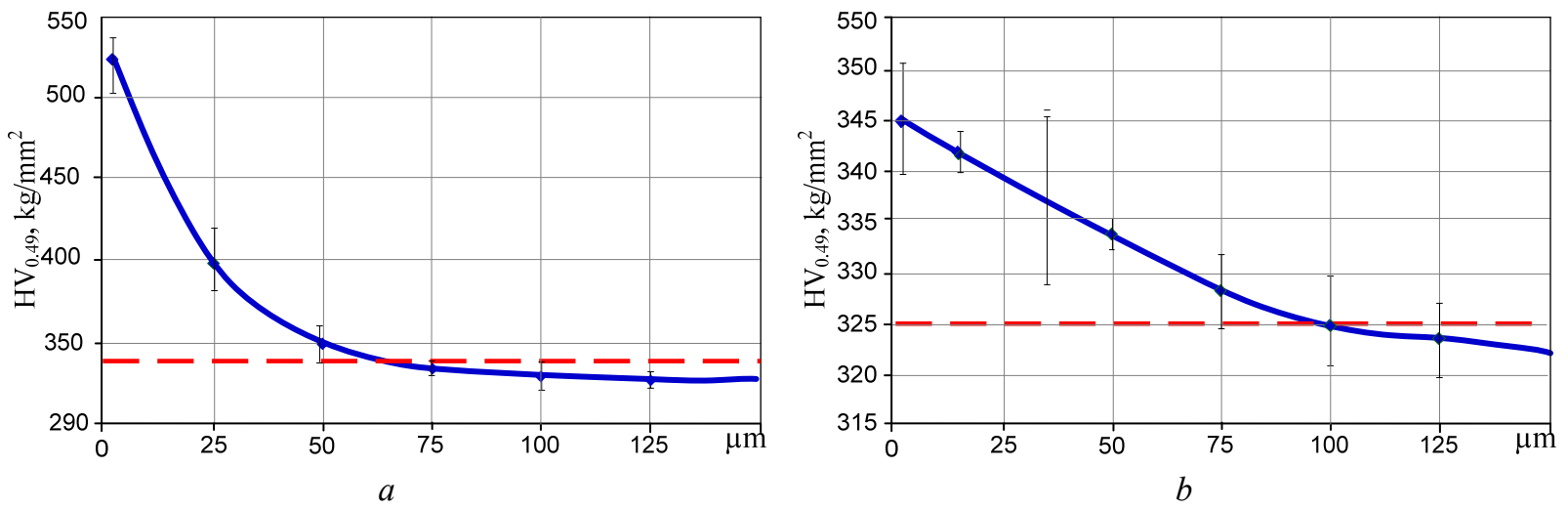

Fig. 8. Distribution of microhardness through the section of specimens of alloy VT16 after CTT $\left(\boldsymbol{P}=1.3 \times 10^{-2} \mathrm{~Pa}\right.$, $\tau=5 \mathrm{~h}$ ) at temperature: $a-650^{\circ} \mathrm{C} ; b-750^{\circ} \mathrm{C}$

Gas-saturation stabilizes the $\alpha$-phase of titanium in surface layer of metal and increases its hardness. The diffusion layer consists of $\alpha$-phase rich layer and transition layer. The $\alpha$-phase rich layer differs in structure from the base metal by increased content of $\alpha$-phase, that is easily revealed with metallography. This layer is represented often by only one $\alpha$-phase. Transition layer is not visibly differ from the base metal, but for this layer the larger hardness is inherent.

Saturation of surface layer by oxygen and in some cases the sublimation of alloying elements lead to the redistribution of alloying elements in the surface layer of metal and changing of its chemical composition on the alloy OT4-1, but on the another alloys such changes are not observed (Fig. 9).
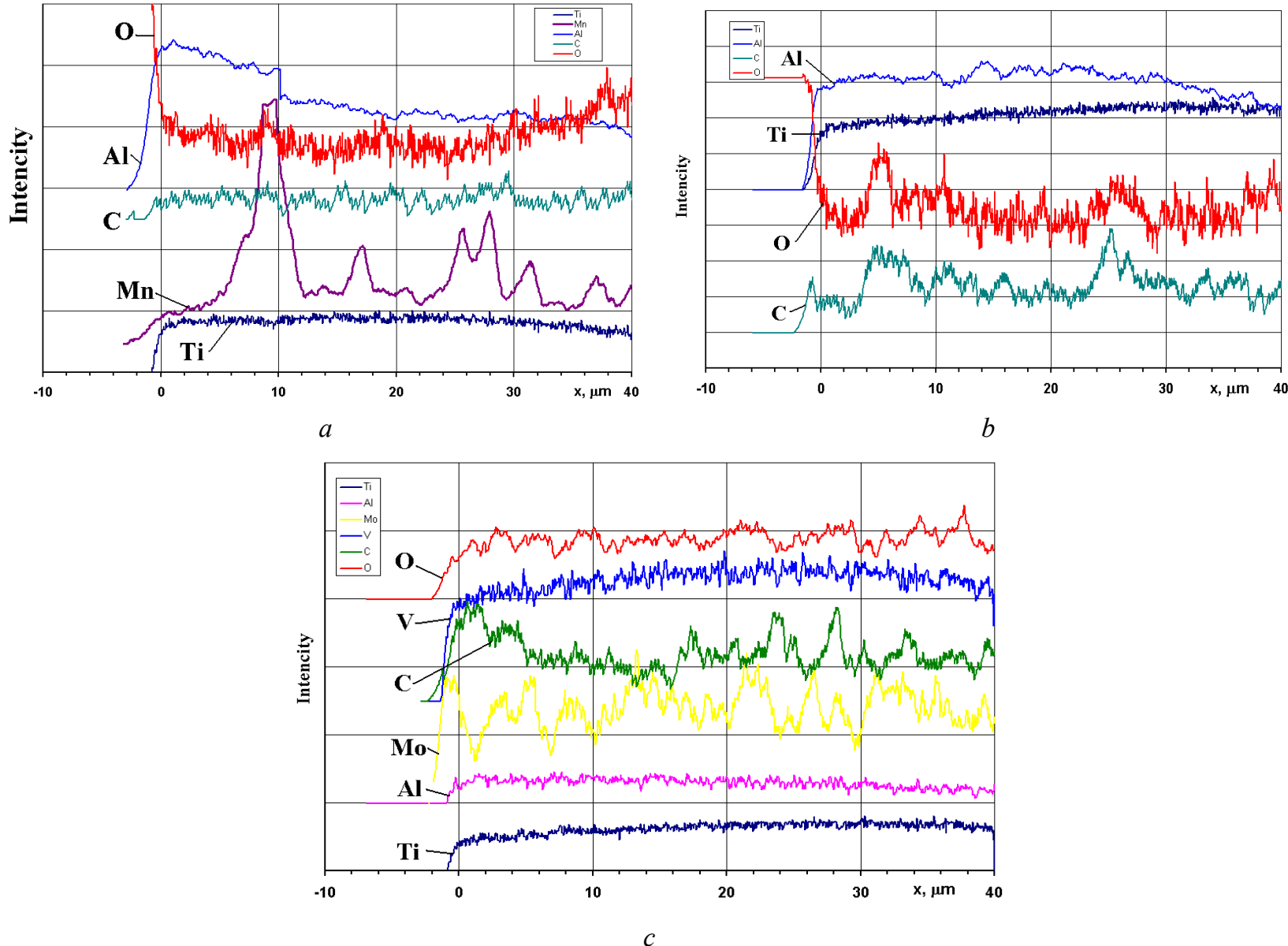

Fig. 9. Distribution of alloying elements in the surface layer of alloy (a) OT4-1, (b) VT5 and (c) VT16 after CTT $\left(\boldsymbol{T}=750^{\circ} \mathrm{C}, \boldsymbol{P}=6.6 \times 10^{-2} \mathrm{~Pa}, \boldsymbol{\tau}=5 \mathrm{~h}\right)$ 


\section{Vasyl Trush}

Effect of oxygen partial pressure on the surface hardness and hardening zone dept.

Apart from the temperature-time parameters, the gas-dynamical parameters of gas medium (partial pressure of chemically active components and dynamics - $\boldsymbol{I}$ of leaking) influence on the level of surface hardening. This influence should be taking into account during prediction of the consequences of thermodiffusion saturation of titanium alloys in the rarefied gas medium.

Let's consider in detail the influence of changing of pressure of gas medium $\left(\boldsymbol{P}=6.6 \times 10^{-2}, 1.33 \times 10^{-}\right.$ $\left.{ }^{2}, 6.6 \times 10^{-3} \mathrm{~Pa}, \boldsymbol{I}=5 \times 10^{-5} \cdot \mathrm{Pa} \cdot \mathrm{s}^{-1}\right)$. The surface hardness and depth of hardened zone most of titanium alloys is increased with increasing of pressure under constant temperature accordingly with the obtained results (Fig. 10). This is most appreciably for $\alpha$-titanium alloys VT1-0 and VT5. The derivation from the regularity mentioned above is observed for pseudo- $\alpha$-alloy OT4-1 and $(\alpha+\beta)$-alloy VT16 alloyed by elements with high volatility of oxides under saturation at $650^{\circ} \mathrm{C}\left(\mathrm{OT} 4-1\right.$, VT16) and $700^{\circ} \mathrm{C}$ (VT16) decreasing of gain of surface hardness. In our opinion, this is caused by activation of sublimation process of $\mathrm{Mn}$ and $\mathrm{V}$ at relatively low intensity of gas saturation process and small solubility of oxygen in $\beta$-phase of titanium. At higher temperatures, the increasing of pressure of gas medium leads to the changing of tendencies in gain of surface hardness: the change in the inclination of temperature dependences is observed, that can be connected with increasing of oxygen flow from the medium, which becomes commensurable with the flow of withdrawal due to diffusion (Fig. 10, c).

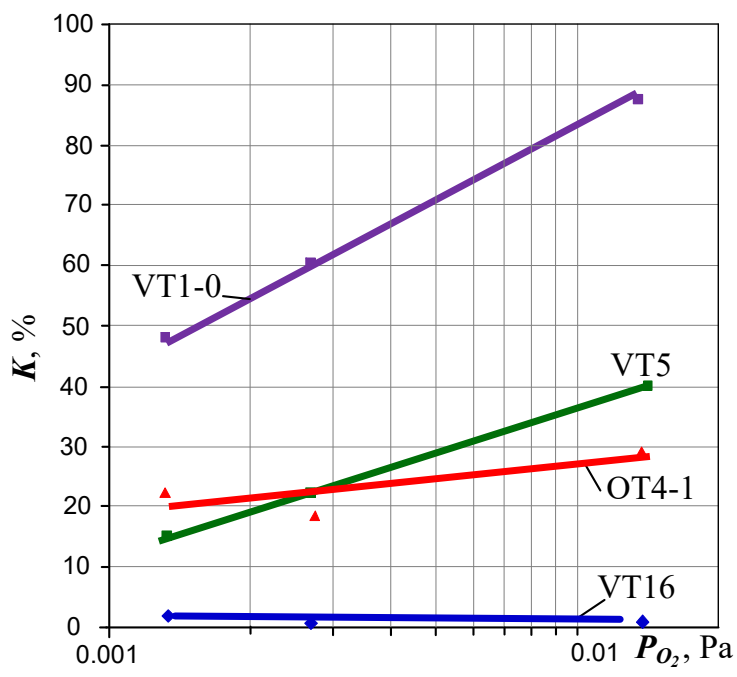

$a$

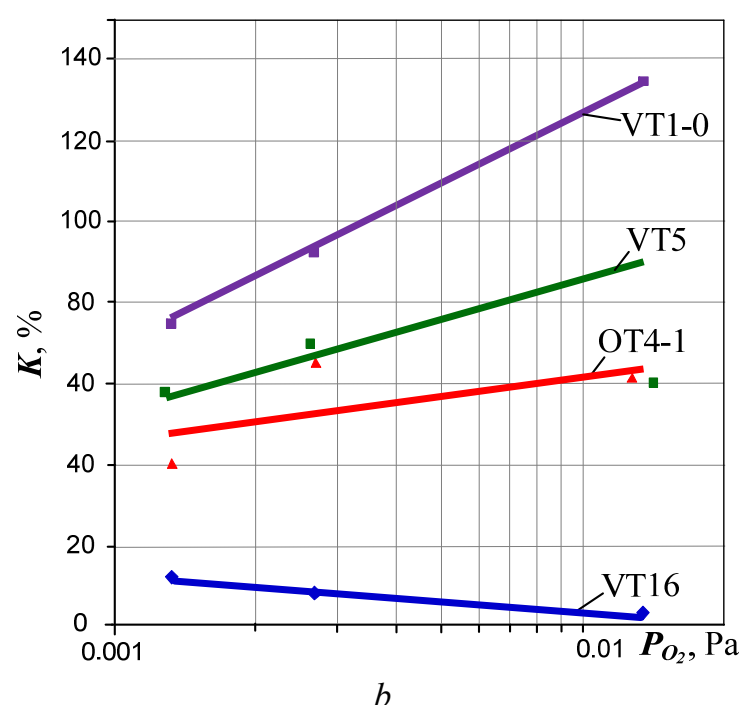

$b$

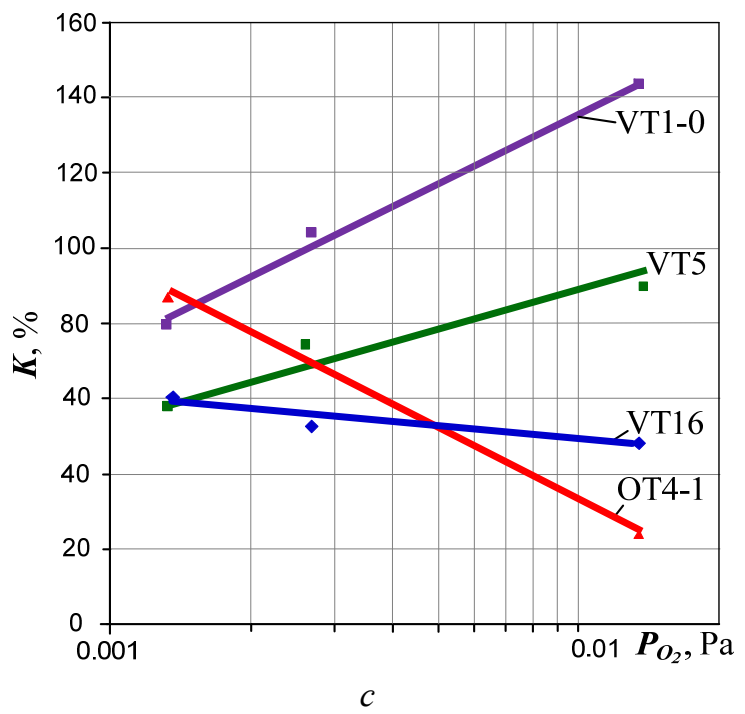

Fig. 10. The relative gain of surface hardness of titanium alloys for $5 \mathrm{~h}$ depending on the oxygen pressure in rarefied gas medium at temperature: $a-650^{\circ} \mathrm{C} ; b-700{ }^{\circ} \mathrm{C} ; c-750{ }^{\circ} \mathrm{C}$ 


\section{Kinetic Regularities of High-temperature Interaction of Titanium Alloys with Oxygen-Medium}

Thermodiffusion saturation was performed under dynamic conditions of rarefied gas medium. That is to say, the residual pressure of medium is determined by dynamic equilibrium of gas flows pumped out and leaking in to the reaction camera from the outside. Rate of leaking should be restricted because the increase of the flow of the leaking gases influences on the kinetics of interaction similarly to the increasing of pressure [5]. It should be noticed that all mentioned results are obtained under the conditions of low enough specific rate of leaking in to the reaction chamber of vacuum equipment $-\boldsymbol{I}=5 \times 10^{-5} \cdot \mathrm{Pa} \cdot \mathrm{s}^{-1}$. Increasing of leaking in to the vacuum system intensifies sufficiently the oxidation and gas saturation of titanium alloys VT1-0, VT5, OT4-1, VT16, however the regularities of this factor were not enough studied.

Relationship between the treatment parameters (pressure, temperature, duration) and level of interstitial solid.

To predict the parameters of surface hardening of titanium alloys as a function of thermodiffusion saturation by interstitial impurities the improved physico-mathematical model of gas saturation of titanium alloys in rarefied gas medium is proposed for using [6].

Intensity of thermodiffusion processes is determined by phase-boundary reaction, concentration distribution of diffusant and diffusion coefficient. Phase-boundary reaction consists of a number of processes occurring in vacuum: adsorption of molecules and atoms of gases of residual atmosphere, their dissolution in the metal, oxidation and etc.; rate of this reaction is changed depending on the degree of medium discharging. Actually, the boundary concentration of oxygen on the surface of metal is not being steadied at once, but is being increased gradually with rate depending on the degree of gas medium discharging. Based on the thermodynamic analysis (see first milestone) the titanium oxides are in the equilibrium with pressure of oxygen at all degrees of discharging, that provides the boundary solubility of oxygen in $\alpha$-titanium - $\boldsymbol{C}_{0}=33$ aт. $\% \mathrm{O}_{2}$, that causes formation of stochiometric oxides [3, 4]. Thus the calculation of diffusion saturation of metal by oxygen mast be performed basing on the next boundary condition [6]:

$$
-D \frac{d C}{d x}=\alpha \cdot\left[C_{0}-C(0, t)\right], x=0,
$$

where $\alpha$ - coefficient of rate of phase-boundary reaction; $\boldsymbol{C}_{0}$ - equilibrium concentration of oxygen in metal; $\boldsymbol{C}(0, \boldsymbol{t})$ - actual concentration; $\boldsymbol{t}$ - time. These boundary conditions describe the mass change for period of time before the formation of oxide with certain thickness, which can already influence substantially on the rate of the processes.

The function $\boldsymbol{C}(\mathbf{x}, \mathbf{t})$ is the known solution of the diffusion task:

$$
C(x, t)=C_{0} \cdot\left[\operatorname{erfc}(x / 2 \sqrt{D t})-\exp \left(h x+h^{2} D t\right) \cdot \operatorname{erfc}(x / 2 \sqrt{D t}+h \sqrt{D t})\right],
$$

where $\boldsymbol{h}=\alpha / \boldsymbol{D}$.

Mass changing of specimen under saturation by oxygen, dimension of diffusion zone up to $150 \mu \mathrm{m}$ and specimen thickness $3 \mathrm{~mm}$, per unit area are approximated by expression [5]:

$$
M(t)=\left(C_{0} / h\right) \cdot\left[\exp \left(h^{2} D t\right) \operatorname{erfc}(h \sqrt{D t})-1+2 h \sqrt{D t / \pi}\right] .
$$

In the framework of physico-mathematical model of interaction of solid with gaseous medium under conditions of third type at the metal / gas interface the coefficients of phase-boundary reaction $(\alpha)$ for alpha titanium alloys VT1-0 and VT5 (see Tab. 7) are determined using the experimental data (Tab. 1).

The proposed approach for describing of the gas-saturation processes with using of coefficient of phase-boundary reaction $\alpha$ allows: to calculate the mass change and concentration distribution of diffusant in the surface layer of metal under various temperature-time regimes of thermodiffusion saturation of $\alpha$ titanium alloys; to determine the characteristics of gas saturated layer (hardness distribution, depth of hardened zone) with using known correlation between hardness of surface layer and concentration of oxygen. The calculated nomograms for determination of permissible parameters of CTT of alloys VT1-0 and VT5 under condition of regulated level of surface hardening $\boldsymbol{K}=25 \%$ is presented on the Fig. 11 . 
Coefficients of phase-boundary reaction (a) for titanium alloys VT1-0 and VT5

\begin{tabular}{|c|c|c|c|c|}
\hline \multirow{2}{*}{ Alloy } & \multirow{2}{*}{$\boldsymbol{T},{ }^{\circ} \mathrm{C}$} & \multicolumn{3}{|c|}{$\alpha(\mathrm{cm} / \mathrm{s})$ at residual pressure of gas medium } \\
\cline { 3 - 5 } & & $\boldsymbol{P}=6.6 \cdot 10^{-3} \mathrm{~Pa}$ & $\boldsymbol{P}=1.33 \cdot 10^{-2} \mathrm{~Pa}$ & $\boldsymbol{P}=6.6 \cdot 10^{-2} \mathrm{~Pa}$ \\
\hline \multirow{3}{*}{ VT1-0 } & 650 & $5.017 \times 10^{-9}$ & $5.792 \times 10^{-9}$ & $7.565 \times 10^{-9}$ \\
\cline { 2 - 5 } & 700 & $1.206 \times 10^{-8}$ & $1.393 \times 10^{-8}$ & $1.819 \times 10^{-8}$ \\
\cline { 2 - 5 } & 750 & $2.662 \times 10^{-8}$ & $3.073 \times 10^{-8}$ & $4.014 \times 10^{-8}$ \\
\hline \multirow{3}{*}{ VT5 } & 650 & $1.76 \times 10^{-9}$ & $2.04 \times 10^{-9}$ & $2.66 \times 10^{-9}$ \\
\cline { 2 - 5 } & 700 & $4.48 \times 10^{-9}$ & $5.18 \times 10^{-9}$ & $6.76 \times 10^{-9}$ \\
\cline { 2 - 5 } & 750 & $1.04 \times 10^{-8}$ & $1.20 \times 10^{-8}$ & $1.56 \times 10^{-8}$ \\
\hline
\end{tabular}

The obtained analytical data are in a good accordance with the experimental results that allow using this approach for evaluation and prediction of parameters of thermodiffusion hardening of surface layer of $\alpha$-titanium alloys.
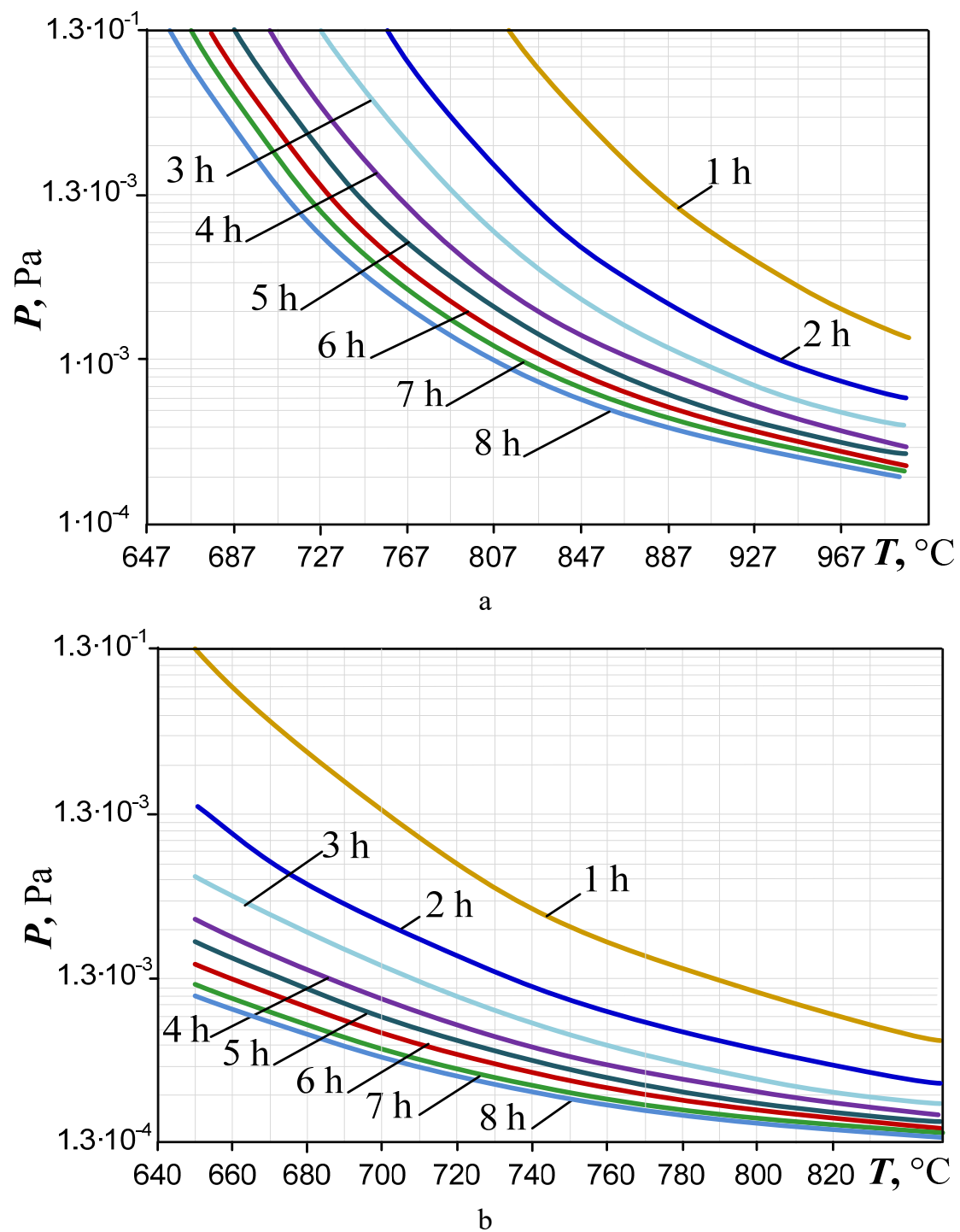

Fig. 11. Nomograms for determination of parameters of CTT of titanium alloy $(a)$ VT1-0 and $(b)$ VT5 (the curves correspond to the level of surface hardening $\boldsymbol{K}=25 \%$ ).

The additional investigation for determination of model dependences for pseudo- $\alpha$ and $(\alpha+\beta)$ titanium alloys is necessary since at the selected temperatures the change in the ratio of phase components in alloys and sublimation of alloying elements during gas saturation are possible. 


\section{Kinetic Regularities of High-temperature Interaction of Titanium Alloys with Oxygen-Medium}

\section{Conclusions}

The kinetic parameters of interaction and regularities of solid-solution hardening of titanium alloys VT1-0, VT5, OT4-1 and VT16 under conditions of thermodiffusion saturation in rarefied gas medium are determined.

It is shown that under the same conditions of saturation $(\boldsymbol{T}, \tau, \boldsymbol{P})$ the hardened layers of various parameters $(\boldsymbol{H}, \boldsymbol{l})$ are formed on the titanium alloys. The monophase $\alpha$-titanium alloys VT1-0, VT5 and pseudo- $\alpha$-alloy OT4-1 are the most sensitive to the conditions of gas-saturation: gain of surface hardness and its gradient in the hardened layer increases sufficiently. With increasing of $\beta$-phase (OT4 $\rightarrow$ VT16) changing of the parameters of CTT has less influence on the hardness of surface layer, but the depth of the hardened zone is being increased with increasing of the temperature and exposure time.

\section{References}

[1] Boyer, R., E.W. Collings, and G. Welsch, Materials Properties Handbook: Titanium Alloys, ASM International: Novelty, OH, 1994.

[2] C. Leyens, M. Peters. Titanium and Titanium Alloys: Fundamentals and Applications; WILEY-VCH Verlag GmbH \& Co., Germany, 2003.

[3] V.N. Moiseyev, Titanium Alloys. Russian aircraft and aerospace applications. London-New YorkSingapore: Taylor \& Francis Group, 2006.

[4] H. Dong, and X. Y. Li, "Oxygen boost diffusion for the deep-case hardening of titanium alloys," Mater. Sci. Eng. A, vol. 280, no. 2, pp. 303-310, Mar. 2000.

[5] A. R. Ebrahimi, F. Zarei, and R. A. Khosroshahi, "Effect of thermal oxidation process on fatigue behavior of Ti-4Al-2V alloy," Surf. Coatings Technol., vol. 203, no. 3-4, pp. 199-203, Nov. 2008.

[6] H. Fukai, H. Iizumi, K. Minarawa, and Ch. Ouchi, "The Effects of the Oxygen-enriched Surface Layer on Mechanical Properties of . $\alpha+\beta$ Type Titanium Alloys," ISIJ Int., vol. 45, no. 1, pp. 133-141, 2005.

[7] T. Ogawa, H. Shibata, K. Tokaji, "The effect of gas nitriding on fatigue behaviour in pure titanium," International Journal of Fatigue, vol. 16, Issue 5, pp. 331-336, 1994.

[8] Y. Luo, H. Jiang, G. Cheng, and H. Liu, "Effect of Carburization on the Mechanical Properties of Biomedical Grade Titanium Alloys," in Journal of Bionic Engineering, vol. 8, Issue 1, 2011, pp. 86-89.

[9] Y.Z. Kim, T. Konno, T. Murakami, T. Narushima, and Ch. Ouchi, "Surface hardening treatment for titanium materials using $\mathrm{Ar}-5 \% \mathrm{CO}$ gas in combination with post heat treatment under vacuum," Materials Transactions, vol. 50, no. 12, pp. 2763-2771, 2009.

[10] Ya. Matychak, V. Fedirko, A. Prytula, and I. Pohrelyuk, "Modeling of diffusion saturation of titanium by interstitial elements under rarefied atmospheres," Defect and Diffusion Forum, vols. 261-262, pp. 47-54, 2007.

[11] G.G. Maksimovich, V.N. Fedirko, Ya.I. Spector, and A.T. Pichugin, Termicheskaya obrabotka titanovykh $i$ alyuminiyevykh splavov $v$ vakuume $i$ inertnykh sredakh [Thermal treatment of titanium and aluminum alloys in vacuum and inert media]. Kyiv, Ukraine: Naykova dumka Publ., 1987. [in Ukrainian].

[12] K.E. Weeks, and F.E. Block, Termodinamicheskiye svoystva 65 elementov, ikh oksidov, galogenidov, karbidov i nitridov [Thermodynamic properties of 65 elements, their oxides, halides, carbides and nitrides]. Moscow, Russia: Metallurgiya Publ, 1965. [in Russian].

[13] E. Fromm, and E. Gebkhardt, Gazy i uglerod v metallakh [Gases and carbon in metals]. Moscow, Russia: Metallurgiya Publ., 1980. [in Russian]

[14] U. Zwicker, Titan i ego splavi [Titanium and its alloys]. Moscow, Russia: Metallurgiya Publ., 1979. [in Russian].

[15] G.G., Maksimovich, V.N. Fedirko, and M.N. Zima, "Effect of the pressure of residual gases of the vacuum atmosphere on oxidation and gas saturation of titanium alloys," Materials Science, vol. 24, no.1, 98-101, 1988.

[16] A.I. Raychenko, Matematicheskaya teoriya diffuzii v prilozheniyakh [Mathematical theory of diffusion in applications]. Kyiv, Ukraine: Naykova dumka Publ., 1981. [in Russian]. 